\title{
EDITORIAL
}

\section{EL DRET, L’ANTROPOCÈ I LA JUSTÍCIA}

\author{
JORDI JARIA I MANZANO \\ Professor Serra Húnter de Dret constitucional i ambiental \\ Universitat Rovira i Virgili \\ Investigador \\ Centre d'Estudis de Dret Ambiental de Tarragona (CEDAT) \\ jordi.jaria@urv.cat
}

Fa quinze anys, el gener de 2002, la revista Nature publicava una nota breu del Premi Nobel de Química Paul J. Crutzen, titulada "Geology of mankind"1. En aquell text, que ha tingut una influència enorme en la construcció de la interpretació actual de la crisi ambiental i, en particular, en la interpretació del canvi climàtic, Crutzen començava per afirmar el següent:

For the past three centuries, the effects of humans on the global environment have escalated. Because of these anthropogenic emissions of carbon dioxide, global climate may depart significantly from natural behaviour for many millennia to come. It seems appropriate to assign the term 'Anthropocene' to the present, in many ways human-dominated, geological epoch, supplementing the Holocene the warm period of the past 10-12 millennia. The Anthropocene could be said to have started in the latter part of the eighteenth century, when analyses of air trapped in polar ice showed the beginning of growing global concentrations of carbon dioxide and methane. This date also happens to coincide with James Watt's design of the steam engine in $1784^{2}$.

\footnotetext{
${ }^{1}$ Vid. CRUTZEN, P. J., “Geology of mankind”, Nature, vol. 415, 2002, p. 23.

${ }^{2}$ Ibid.
} 
Es tractava de la primera menció d'un concepte que, des d'aleshores ençà, ha fet fortuna per descriure el canvi substancial que representa la consolidació de l'acció humana com a factor transformador de la seva pròpia base biofísica, de manera que la configuració del Sistema Terra passa a ser determinada per una variable endògena singular, la qual cosa suposa un canvi paradigmàtic en relació amb l'evolució precedent. El mateix autor reconeixia que aquesta idea havia estat apuntada per altres persones abans que ell $\mathrm{i}$, de fet, fa remuntar aquesta presa de consciència al geòleg Antonio Stopani, que havia parlat de l'era antropozoica més d'un segle abans, el $1873^{3}$. Efectivament, des que va produir-se la Revolució Industrial, que suposà un salt qualitatiu en l'ús d'energia d'origen fòssil per part dels éssers humans, diverses veus, des de diversos punts de vista, han posat de manifest l'augment progressiu de la capacitat antròpica de transformació de la base biofísica de la reproducció social.

En aquest sentit, la bomba atòmica hauria definit un nou estadi de conscienciació en relació amb aquesta capacitat, a partir de la qual es cobra consciència del caràcter autoreferencial i potencialment autodestructiu dels processos de reproducció social, como posa de manifest el sociòleg Alberto Melucci ${ }^{4}$. Així, la possibilitat per part de l'ésser humà de transformar la biosfera, fins al punt de poder posar en perill les condicions que fan possible la mateixa vida humana en el Sistema Terra, pren volada durant la Guerra Freda i esdevé el punt d'arrencada de la preocupació per la transformació antròpica de la biosfera que donarà la matriu hermenèutica de la crisi ambiental $^{5}$. La presa de consciència sobre els efectes del potencial de modificació de la base biofísica de la reproducció social implícita en l'evolució econòmica i tecnològica de l'espècie humana es produirà cap al final de la dècada dels seixanta, quan es comencen a desplegar les polítiques ambientals i es comença a desenvolupar el dret ambiental, que, des d'aquesta perspectiva, esdevenen no pas una reacció sectorial en el context de l'enginyeria social de patró modern, sinó un reconstrucció de la disciplina social continguda en les estratègies institucionals i en els instruments jurídics ${ }^{6}$.

\footnotetext{
${ }^{3}$ Ibid.

${ }^{4}$ Vid. MELUCCI, A., Vivencia y convivencia. Teoría social para una era de la información, Trotta, Madrid, 2001 (edició castellana de Jesús Casquette), p. 29.

${ }^{5}$ Vid. JARIA I MANZANO, J., La cuestión ambiental y la transformación de lo público, Tirant lo Blanch, Valencia, 2011, p. 129ss.

${ }^{6}$ Això, òbviament, és quelcom debatut. Així, des d'una perspectiva gerencial en relació amb la crisi ambiental, el dret ambiental seria un mer nou sector d'ordenació. Aquesta ha estat qüestió àmpliament discutida per la comunitat iusambientalista a Espanya, sobretot en els primers anys d'evolució del dret
} 
Amb el final de la Guerra Freda, l'amenaça nuclear serà substituïda pel canvi climàtic com a patró dominant en la construcció iconogràfica de la capacitat de transformació de la biosfera adquirida pels éssers humans ${ }^{7}$. En aquest context, es desplegaran estratègies negacionistes, estratègies reformistes i estratègies rupturistes, davant d'una problemàtica que interpel-la la humanitat en el seu conjunt. En el desplaçament conceptual des del perill nuclear a l'alteració climàtica, apareix l'article esmentat de Paul Crutzen, que té el mèrit d'encunyar una expressió que aconsegueix fer-se forat per expressar la transició d'una humanitat sotmesa a les forces de la natura a una humanitat mestressa del seu destí i del Sistema Terra en el seu conjunt ${ }^{8}$.

Allò que es denota mitjançant l'expressió 'Antropocè' és prou acceptable com a descripció acurada de la realitat i, en aquest sentit, poden coincidir-hi negacionistes del canvi climàtic, propugnadors del desenvolupament sostenible - com a estratègia gerencial per governar la modificació antròpica del Sistema Terra—, i partidaris d'una transformació social radical. En definitiva, del que es tracta es de reconèixer el potencial adquirit per l'espècie humana de manipular el seu propi entorn de vida. Tanmateix, l'expressió 'Antropocè', encunyada en l'àmbit de les ciències naturals, en tant que remet al vocabulari propi de la geologia i és posada en circulació per un Premi Nobel de Química, pot amagar una certa indiferència moral o política, tot obviant les qüestions de distribució i de responsabilitat en relació amb els efectes derivats del domini tecnològic del Sistema Terra per part dels éssers humans.

En aquest sentit, en l'article citat de 2007, que Crutzen signa juntament amb Will Steffen, químic, i John R. McNeill, historiador, es consideren fonamentalment dos opcions possibles davant dels reptes socials que representa l'entrada en l'Antropocè, a

ambiental. En aquest sentit, cal veure la posició del que podria ser qualificat com el seu pare, $\mathrm{R}$. MARTÍN MATEO. Vid., particularment, el seu treball Tratado de Derecho ambiental (I), Trivium, Madrid, 1991, p. 83. Més enllà de la construcció dogmàtica d'una branca sectorial específica del dret públic i, particularment, del dret administratiu, es tractaria d'avançar cap a una transformació de la cultura jurídica en el seu conjunt, la qual cosa lligaria amb l'encarament dels reptes socials que imposa l'Antropocè.

${ }^{7}$ Vid. KISS, CH. A., SHELTON, D., Manual of European Environmental Law, Cambridge University Press, Cambridge, 1993, p. 10.

${ }^{8}$ Així, W. STEFFEN, P. J. CRUTZEN i J. R. McNEILL, en un treball posterior al seminal del mateix Crutzen, citat més amunt, "The Anthropocene: Are Humans Now Overwhelming the Great Forces of Nature?", Ambio 36 (8), 2007, p. 615, assenyalen que "Preindustrial societies could and did modify coastal and terrestrial ecosystems but they did not have the numbers, social and economic organisation, or technologies needed to equal or dominate the great forces of Nature in magnitude or rate". La diferència amb l'era industrial seria que, efectivament, els humans passen a dominar les "grans forces de la natura", la qual cosa caracteritzaria l'Antropocè, com a període geològic basat en la multiplicació de la capacitat transformadora dels éssers humans a partir de l'ús intensiu d'energia d'origen fòssil. 
saber, business-as-usual, tot i que assenyalen les possibles insuficiències d'una evolució tecnològica sense un canvi de valors socials; i la geoenginyeria, encara que reconeixen que hi ha qüestions morals serioses en relació amb això i, d'altra banda, són conscients de la incertesa que presideix aquesta via, de manera que no es poden anticipar efectes secundaris més greus que els assoliments que puguin aconseguir-s'hi ${ }^{9}$. En tot cas, els autors no prenen en consideració una revisió radical dels pressupòsits culturals de la Modernitat occidental, que implícitament descriuen com una evolució natural i positiva de la humanitat en el seu conjunt, d'acord amb el discurs salvífic dominant en aquest context; ni tampoc no es refereixen al fet de què les conseqüències de l'Antropocè deriven no pas de l'acció antròpica en general, sinó del desplegament d'una determinada estructura socioeconòmica, el sistema-món capitalista, a partir de l'acció d'una determinada part de la població mundial, la situada en el centre d'aquest sistemamón ${ }^{10}$.

Aquesta perspectiva, aparentment cega al caràcter desigual del metabolisme social, tendeix a atribuir a una evolució natural de l'espècie humana en el seu conjunt el que és el resultat d'un determinat procés social, que desplega unes estructures de dominació i que és intrínsecament inequitatiu, ja que depèn de la confluència dels recursos del centre a la perifèria ${ }^{11}$. És per aquest motiu que ha estat discutida. Això ha contaminat la mateixa expressió 'Antropocè', en la mesura que ha estat considerada una noció esbiaixada, mitjançant la qual es provaria d'ocultar sota la suggestió d'una acció conjunta de l'espècie humana, els desequilibris, les inequitats i les responsabilitats internes del desplegament del procés d'acumulació capitalista, que acaba generant la situació de transformació antròpica de la biosfera ${ }^{12}$.

Així, d'alguna manera, la noció d'Antropocè, tal com es concebuda en la seva formulació originària, seria susceptible de promoure una narrativa neomalthusiana, de

\footnotetext{
${ }^{9}$ Vid. op. cit., p. 619-620.

${ }^{10}$ En relació amb els orígens i els pressupòsits de l'economia-món capitalista, vid. WALLERSTEIN, I., El moderno sistema mundial. I. La agricultura capitalista y los orígenes de la economía-mundo en el siglo XVI, Siglo XXI, Madrid, $2010^{2}$ (versió castellana de Antonio Resines).

${ }^{11}$ Vid. JARIA I MANZANO, J., "La externalización de costes ambientales en el acceso a los recursos naturales: marco institucional y distribución inequitativa", Working Paper $\mathrm{n}^{\circ} .4$, Proyecto Del desarrollo sostenible a la justicia ambiental: Hacia una matriz conceptual para la gobernanza global (DER201344009-P), Ministerio de Economía y Competitividad (España), 2017, <http://www.dretpublic.urv.cat/media/upload/domain_89/arxius/Working\%20Paper\%20n\%C2\%BA\%204_1.pdf> [última visita el 24 de enero de 2017].

${ }^{12}$ Vid. MALM, A., HORNBORG, A., "The geology of mankind? A critique of the Anthropocene narrative", The Anthropocene Review, Vol. 1(1), 2014, p. 62-69.
} 
manera que el potencial de destrucció de l'espècie humana vindria determinat, fonamentalment, per l'augment de la població correlatiu al consum creixent d'energia, la qual cosa representaria, en última instància, atribuir les responsabilitats en relació amb la crisi ambiental al conjunt de la humanitat i no pas a una fracció determinada d'éssers humans ${ }^{13}$. A partir d'aquesta crítica, tot i reconèixer el potencial descriptiu de l'expressió 'Antropocé', així com les exigències en relació amb l'ordenació de l'acció social que planteja el potencial de transformació adquirit per l'espècie humana en relació amb el Sistema Terra, cal introduir les qüestions relatives a l'equitat en el relat que promou sobre la conquesta humana de la biosfera, domini — no es pot deixar de banda - incert en relació amb les seves conseqüències, la qual cosa té implicacions morals no pas banals ${ }^{14}$.

En definitiva, des de la presa de consciència de la capacitat de transformació antròpica de la biosfera, cal avançar cap a una distribució equitativa de les càrregues i beneficis del metabolisme social, cosa que ve propugnada per la idea de justícia ambiental. En aquest sentit, la consciència del potencial de transformació humana, que obligaria a reconsiderar l'estructura institucional i les tècniques de disciplina social per governar adequadament l'acció antròpica en relació amb el seu impacte en la configuració del Sistema Terra, s'hauria de canalitzar a través d'estratègies d'acció social conscients del caràcter inequitatiu dels processos de transformació antròpica fins al present, tot introduint la noció de justícia ambiental, tant en l'eix sincrònic, com en l'eix diacrònic. D'aquesta manera, la resposta social davant dels reptes que suposa l'Antropocè no seria un mer expedient tècnic, adreçat a mantenir les relacions de poder existents, sinó que exigiria una transformació profunda, en què s'haurien de fer efectives les responsabilitats sobre els processos de modificació de la biosfera, així com s'hauria d'avançar cap a la distribució equitativa del metabolisme social.

Aquesta perspectiva interpel-la clarament ja no només les ciències naturals o dures, sinó també els científics socials; més encara, als diversos actors capaços de produir coneixement, fins i tot fora dels àmbits acadèmics formals. És evident que aquí hi ha un paper per als juristes, que no poden ser aliens a les conseqüències en l'organització

${ }^{13}$ Vid. op. cit., p. 65. Sobre l'opció neomalthusiana com a camí cap a la sostenibilitat, vid. JOSITSCH, D., "Das Konzept der nachhaltigen Entwicklung (Sustainable Development) im Völkerrecht und seine innerstaatliche Umweltsetzung", Umweltrecht in der Praxis / Le Droit de l'environnement dans la pratique, 1997, p. 97.

${ }^{14}$ Vid. JONAS, H., El principio de responsabilidad - Ensayo de una ética para la civilización tecnológica, Herder, Barcelona, 1995 (versión castellana de José María Fernández Retenaga), p. 56. 
social i, per tant, en l'eina fonamental per disciplinar-la, el dret, de l'entrada en l'era de l'Antropocè ${ }^{15}$. En aquest sentit, cal fer front a la responsabilitat històrica - que es fa visible en expressions com ara 'deute ecològic' o 'deute climàtic'—16, la inequitat present —que es materialitza en l'intercanvi ecològicament desigual en el context de la diferenciació centre-perifèria en l'economia-món capitalista ${ }^{17}$, i la sostenibilitat futura en relació amb la transformació antròpica del Sistema Terra.

És evident que això planteja desafiaments molt significatius als juristes, que no es poden refugiar en les categories tradicionals, sinó que han d'assumir, al mateix temps, el repte d'incorporar-se a la generació de coneixement interdisciplinar requerit en aquesta nova fase de l'evolució social, així com a la necessitat de reconstruir el seu discurs i les seves concepcions, amb la finalitat última de generar instruments adequats per afrontar les problemàtiques que es generen en un context de creació social del Sistema Terra. En l'àmbit de la tradició continental, això significa, entre altres coses, una reavaluació de la cultura dels drets i de la diferenciació entre esfera pública i esfera privada, fonamental en la tradició constitucional i la construcció del dret públic modern; una reconsideració de les qüestions relatives a la titularitat dels béns i a la responsabilitat, cosa que impacta sobre les nocions nuclears al voltant de les quals s'ha desenvolupat la tradició civilista; així com una reinvenció metodològica, més enllà de les categories i les pràctiques heretades de la pandectística, que han configurat la cultura jurídica i la socialització professionals dels juristes continentals en el trànsit de l'Holocè fins a l'Antropocè.

\footnotetext{
${ }^{15}$ Vid. COCCIOLO, E., "La unión de la energía y la gobernanza del Sistema Tierra en el Antropoceno: una cuestión constitucional”, Revista Catalana de Dret Ambiental, vol. 6 (1), 2015, p. 35. Una aproximació panoràmica molt recent en aquesta dirección seria la de KOTZÉ, L., en Global Environmental Constitutionalism in the Anthropocene, Hart, Oxford-Portland, 2016.

${ }^{16}$ Vid. MARTÍNEZ-ALIER, J., "The Ecological Debt”, Kurswechsel, núm. 4, 2002, p. 5-16, en relació amb el deute ecològic; i BORRÀS PENTINAT, S., FELIPE PÉREZ, B., "El régimen jurídico del cambio climático: entre la justicia climática y los derechos humanos", Working Paper no. 2, Proyecto Del desarrollo sostenible a la justicia ambiental: Hacia una matriz conceptual para la gobernanza global (DER2013-44009-P), Ministerio de Economía y Competitividad (España), 2017, <http://www.dretpublic.urv.cat/media/upload/domain_89/arxius/Working\%20Paper\%20n\%C2\%BA\%204_1.pdf>, p. 32ss. [última visita el 31 de enero de 2017], en relació amb el deute climàtic.

${ }^{17}$ Vid. HORNBORG, A., "Zero-Sum World. Challenges in Conceptualizing Environmental Load Displacement and Ecologically Unequal Exchange in the World-System", International Journal of Comparative Sociology, vol. 50 (3-4), 2009, p. 237-262.
} 


\title{
EDITORIAL
}

\section{EL DERECHO, EL ANTROPOCENO Y LA JUSTICIA}

\author{
JORDI JARIA I MANZANO \\ Profesor Serra Húnter de Derecho constitucional y ambiental \\ Universitat Rovira i Virgili \\ Investigador \\ Centre d'Estudis de Dret Ambiental de Tarragona (CEDAT) \\ jordi.jaria@urv.cat
}

Hace quince años, en enero de 2002, la revista Nature publicaba una nota breve del Premio Nobel de Química Paul J. Crutzen, titulada "Geology of mankind"18. En aquel texto, que ha tenido una influencia enorme en la construcción de la interpretación actual de la crisis ambiental y, en particular, en la interpretación del cambio climático, Crutzen empezaba por afirmar lo siguiente:

For the past three centuries, the effects of humans on the global environment have escalated. Because of these anthropogenic emissions of carbon dioxide, global climate may depart significantly from natural behaviour for many millennia to come. It seems appropriate to assign the term 'Anthropocene' to the present, in many ways human-dominated, geological epoch, supplementing the Holocene the warm period of the past 10-12 millennia. The Anthropocene could be said to have started in the latter part of the eighteenth century, when analyses of air trapped in polar ice showed the beginning of growing global concentrations of carbon dioxide and methane. This date also happens to coincide with James Watt's design of the steam engine in $1784^{19}$.

\footnotetext{
${ }^{18}$ Vid. CRUTZEN, P. J., "Geology of mankind”, Nature, vol. 415, 2002, p. 23.

19 Ibid.
} 
Se trataba de la primera mención de un concepto que, desde entonces, ha hecho fortuna para describir el cambio sustancial que representa la consolidación de la acción humana como factor transformador de su propia base biofísica, de modo que la configuración del Sistema Tierra pasa a ser determinada por una variable endógena singular, lo que supone un cambio paradigmático en relación con la evolución precedente. El mismo autor reconocía que esta idea había sido apuntada por otras personas antes que él y, de hecho, hace remontar esta toma de conciencia al geólogo Antonio Stopani, que había hablado de la era antropozoica más de un siglo antes, en $1873^{20}$. Efectivamente, desde que se produjo la Revolución Industrial, que supuso un salto cualitativo en el uso de energía de origen fósil por parte de los seres humanos, distintas voces, desde distintos puntos de vista, han puesto de manifiesto el aumento progresivo de la capacidad antrópica de transformación de la base biofísica de la reproducción social.

En este sentido, la bomba atómica habría definido un nuevo estadio de concienciación en relación con esta capacidad, a partir de la cual se cobra conciencia del carácter autoreferencial y potencialmente autodestructivo de los procesos de reproducción social, como pone de manifiesto el sociólogo Alberto Melucci ${ }^{21}$. Así, la posibilidad por parte del ser humano de transformar la biosfera, hasta el punto de poder poner en peligro las condiciones que hacen posible la propia vida humana en el Sistema Tierra, cobra importancia durante la Guerra Fría y deviene el punto de arranque de la preocupación por la transformación antrópica de la biosfera que proporcionará la matriz hermenéutica de la crisis ambiental ${ }^{22}$. La toma de conciencia sobre los efectos del potencial de modificación de la base biofísica de la reproducción social implícita en la evolución económica y tecnológica de la especie humana se producirá hacia el final de la década de los sesenta, cuando se empiecen a desplegar las políticas ambientales y se empiece a desarrollar el Derecho ambiental, que, desde esta perspectiva, devienen no solo una reacción sectorial en el contexto de la ingeniería social de patrón moderno,

\footnotetext{
${ }^{20}$ Ibid.

${ }^{21}$ Vid. MELUCCI, A., Vivencia y convivencia. Teoría social para una era de la información, Trotta, Madrid, 2001 (edición castellana de Jesús Casquette), p. 29.

${ }^{22}$ Vid. JARIA I MANZANO, J., La cuestión ambiental y la transformación de lo público, Tirant lo Blanch, Valencia, 2011, p. 129ss.
} 
sino una reconstrucción de la disciplina social contenida en las estrategias institucionales y en los instrumentos jurídicos ${ }^{23}$.

Con el final de la Guerra Fría, la amenaza nuclear será sustituida por el cambio climático como patrón dominante en la construcción iconográfica de la capacidad de transformación de la biosfera adquirida por los seres humanos ${ }^{24}$. En este contexto, se desplegaran estrategias negacionistas, estrategias reformistas y estrategias rupturistas, ante una problemática que interpela a la humanidad en su conjunto. En el desplazamiento conceptual desde el peligro nuclear a la alteración climática, aparece el mencionado artículo de Paul Crutzen, que tiene el mérito de acuñar una expresión que consigue hacerse sitio para expresar la transición de una humanidad sometida a las fuerzas de la naturaleza a una humanidad que domina su destino y el del Sistema tierra en su conjunto ${ }^{25}$.

Aquello que se denota mediante la expresión 'Antropoceno' es suficientemente aceptable como descripción apropiada de la realidad y, en este sentido, pueden coincidir negacionistas del cambio climático, propugnadores del desarrollo sostenible —como estrategia gerencial para gobernar la modificación antrópica del Sistema Tierra-, y partidarios de una transformación social radical. En definitiva, de lo que se trata es de reconocer el potencial adquirido por la especie humana de manipular su propio entorno de vida. Sin embargo, la expresión 'Antropoceno', acuñada en el ámbito de las ciencias naturales, en tanto que remite al vocabulario propio de la geología y es puesta en circulación por un Premio Nobel de Química, puede ocultar una cierta indiferencia

\footnotetext{
${ }^{23}$ Esto, obviamente, es algo debatido. Así, desde una perspectiva gerencial en relación con la crisis ambiental, el Derecho ambiental sería un mero nuevo sector de ordenación. Esto ha sido ampliamente debatido por la comunidad iusambientalista en España, sobre todo en los primeros años de evolución del Derecho ambiental. En este sentido, debe tenerse en cuenta la posición del que podría ser calificado como su padre, R. MARTÍN MATEO. Vid., particularmente, su trabajo Tratado de Derecho ambiental (I), Trivium, Madrid, 1991, p. 83. Más allá de la construcción dogmática de una rama sectorial específica del Derecho público y, en particular, del Derecho administrativo, se trataría de avanzar hacia una transformación de la cultura jurídica en su conjunto, lo que enlazaría con el afrontar los retos sociales que impone el Antropoceno.

${ }^{24}$ Vid. KISS, CH. A., SHELTON, D., Manual of European Environmental Law, Cambridge University Press, Cambridge, 1993, p. 10.

${ }^{25}$ Así, W. STEFFEN, P. J. CRUTZEN i J. R. McNEILL, en un trabajo posterior al seminal del propio Crutzen, citado más arriba, "The Anthropocene: Are Humans Now Overwhelming the Great Forces of Nature?", Ambio 36 (8), 2007, p. 615, señalan que "Preindustrial societies could and did modify coastal and terrestrial ecosystems but they did not have the numbers, social and economic organisation, or technologies needed to equal or dominate the great forces of Nature in magnitude or rate". La diferencia con la era industrial sería que, efectivamente, los humanos pasan a dominar las "grandes fuerzas de la naturaleza", lo que caracterizaría al Antropoceno, como período geológico basado en la multiplicación de la capacidad transformadora de los seres humanos a partir del uso intensivo de la energía de origen fósil.
} 
moral o política, obviando las cuestiones de distribución y responsabilidad en relación con los efectos derivados del dominio tecnológico del Sistema Tierra por parte de los seres humanos.

En este sentido, en el artículo citado de 2007, que Crutzen firma conjuntamente ocn Will Steffen, químico, y John R. McNeill, historiador, se consideran fundamentalmente dos opciones posibles ante los retos sociales que supone la entrada en el Antropoceno, a saber, business-as-usual, aunque señalan las posibles insuficiencias de una evolución tecnológica sin un cambio de valores sociales; y la geoingeniería, aunque reconocen que hay cuestiones morales serias en relación con esto y, por otra parte, son conscientes de la incertidumbre que preside esta vía, de manera que no pueden anticiparse efectos secundarios más graves que los logros que puedan conseguirse ${ }^{26}$. En todo caso, los autores no toman en consideración una revisión radical de los presupuestos culturales de la Modernidad occidental, que implícitamente describen como una evolución natural y positiva de la humanidad en su conjunto, de acuerdo con el discurso salvífico dominante en este contexto; ni tampoco se refieren al hecho de que las consecuencias del Antropoceno no derivan de la acción antrópica en general, sino del despliegue de una determinada estructura socioeconómica, el sistema-mundo capitalista, a partir de la cción de una determinada parte de la población mundial, la situada en el centro de este sistema-mundo ${ }^{27}$.

Esta perspectiva, aparentemente ciega al carácter desigual del metabolismo social, tiende a atribuir a una evolución natural de la especie humana en su conjunto lo que es el resultado de un determinado proceso social, que despliega una estructuras de dominación y que es intrínsecamente inequitativo, ya que depende de la confluencia de los recursos del centro a la periferia ${ }^{28}$. Es por este motivo que ha sido discutida. Esto ha contaminado la misma expresión 'Antropoceno', en la medida en que ha sido considerada una noción sesgada, mediante la cual se intentaría ocultar, bajo la sugestión

\footnotetext{
${ }^{26}$ Vid. op. cit., p. 619-620.

${ }^{27}$ En relación con los orígenes y presupuestos de la economía-mundo capitalista, vid. WALLERSTEIN, I., El moderno sistema mundial. I. La agricultura capitalista y los orígenes de la economía-mundo en el siglo XVI, Siglo XXI, Madrid, $2010^{2}$ (versión castellana de Antonio Resines).

${ }^{28}$ Vid. JARIA I MANZANO, J., "La externalización de costes ambientales en el acceso a los recursos naturales: marco institucional y distribución inequitativa", Working Paper $\mathrm{n}^{\circ}$. 4, Proyecto Del desarrollo sostenible a la justicia ambiental: Hacia una matriz conceptual para la gobernanza global (DER201344009-P), Ministerio de Economía y Competitividad (España), 2017, <http://www.dretpublic.urv.cat/media/upload/domain_89/arxius/Working\%20Paper\%20n\%C2\%BA\%204_1.pdf>[última visita el 24 de enero de 2017].
} 
de una acción conjunta de la especie humana, los desequilibrios, las inequidades y las responsabilidades internas del despliegue del proceso de acumulación capitalista, que acaba generando la situación de transformación antrópica de la biosfera ${ }^{29}$.

Así, de algún modo, la noción de Antropoceno, tal como es concebida en su formulación originaria, sería susceptible de promover una narrativa neomalthusiana, de modo que el potencial de destrucción de la especie humana vendría determinado, fundamentalmente, por el aumento de la población correlativo al consumo creciente de energía, lo que supondría, en última instancia, atribuir las responsabilidades en relación con la crisis ambiental al conjunto de la humanidad y no a una fracción determinada de seres humanos ${ }^{30}$. A partir de esta crítica, reconociendo el potencial descriptivo de la expresión 'Antropoceno', así como las exigencias en relación con la ordenación de la acción social que plantea el potencial de transformación adquirido por la especie humana en relación con el Sistema Tierra, deben introducirse las cuestiones relativas a la equidad en el relato que promueve sobre la conquista humana de la biosfera, domino —no puede dejarse de lado- incierto en relación con sus consecuencias, lo que tiene implicaciones morales para nada banales ${ }^{31}$.

En definitiva, desde la toma de conciencia de la capacidad de transformación antrópica de la biosfera, debe avanzarse hacia una distribución equitativa de las cargas y beneficios del metabolismo social, lo que viene propugnado por la idea de justicia ambiental. En este sentido, la conciencia del potencial de transformación humana, que obligaría a reconsiderar la estructura institucional y las técnicas de disciplina social para gobernar adecuadamente la acción antrópica en relación con su impacto en la configuración del Sistema Tierra, lo que debería canalizarse a través de estrategias de acción social conscientes del carácter inequitativo de los procesos de transformación antrópica hasta el presente, introduciendo la noción de justicia ambiental, tanto en el eje sincrónico, como en el eje diacrónico. De este modo, la respuesta social ante los retos que supone el Antropoceno no sería un mero expediente técnico, dirigido a mantener las

\footnotetext{
${ }^{29}$ Vid. MALM, A., HORNBORG, A., "The geology of mankind? A critique of the Anthropocene narrative", The Anthropocene Review, Vol. 1(1), 2014, p. 62-69.

${ }^{30}$ Vid. op. cit., p. 65. Sobre l'opció neomalthusiana com a camí cap a la sostenibilitat, vid. JOSITSCH, D., "Das Konzept der nachhaltigen Entwicklung (Sustainable Development) im Völkerrecht und seine innerstaatliche Umweltsetzung", Umweltrecht in der Praxis / Le Droit de l'environnement dans la pratique, 1997, p. 97.

${ }^{31} \mathrm{Vid}$. JONAS, H., El principio de responsabilidad - Ensayo de una ética para la civilización tecnológica, Herder, Barcelona, 1995 (versión castellana de José María Fernández Retenaga), p. 56.
} 
relaciones de poder existentes, sino que exigiría una transformación profunda, en la que deberían hacerse efectivas las responsabilidades sobre los procesos de modificación de la biosfera, así como debería avanzarse hacia la distribución equitativa del metabolismo social.

Esta perspectiva interpela claramente ya no solo a las ciencias naturales o duras, sino también a los científicos sociales; más aún, a los diferentes actores capaces de producir conocimiento, incluso fuera de los ámbitos académicos formales. Es evidente que aquí hay un rol para los juristas, que no pueden ser ajenos a las consecuencias en la organización social y, por lo tanto, en la herramienta fundamental para disciplinarla, el Derecho, de la entrada en la era del Antropoceno ${ }^{32}$. En este sentido, debe hacerse frente a la responsabilidad histórica-que se hace visible en expresiones como 'deuda ecológica' o 'deuda climática'_ ${ }^{33}$, la inequidad presente-que se materializad en el intercambio ecológicamente desigual en el contexto de la diferenciación centro-periferia en la economía-mundo capitalista ${ }^{34}$, y la sostenibilidad futura en relación con la transformación antrópica del Sistema Tierra.

Es evidente que esto plantea desafíos muy significativos a los juristas, que no se pueden refugiar en las categorías tradicionales, sino que deben asumir, al mismo tiempo, el reto de incorporarse a la generación de conocimiento interdisciplinar requerido en esta nueva fase de la evolución social, así como a la necesidad de reconstruir su discurso y sus concepciones, con la finalidad última de generar instrumentos adecuados para afrontar las problemáticas que se generan en un contexto de creación social del Sistema Tierra. En el ámbito de la tradición continental, esto significa, entre otras cosas, una reevaluación de la cultura de los derechos y de la diferenciación entre esfera pública y esfera privada, fundamental en la tradición constitucional y en la construcción del

\footnotetext{
32 Vid. COCCIOLO, E., "La unión de la energía y la gobernanza del Sistema Tierra en el Antropoceno: una cuestión constitucional", Revista Catalana de Dret Ambiental, vol. 6 (1), 2015, p. 35. Una muy reciente aproximación panorámica en esta dirección sería la de KOTZÉ, L., en Global Environmental Constitutionalism in the Anthropocene, Hart, Oxford-Portland, 2016.

${ }^{33}$ Vid. MARTÍNEZ-ALIER, J., "The Ecological Debt”, Kurswechsel, núm. 4, 2002, p. 5-16, en relación con la deuda ecológica; i BORRÀS PENTINAT, S., FELIPE PÉREZ, B., "El régimen jurídico del cambio climático: entre la justicia climática y los derechos humanos", Working Paper $\mathrm{n}^{\circ}$. 2, Proyecto Del desarrollo sostenible a la justicia ambiental: Hacia una matriz conceptual para la gobernanza global (DER2013-44009-P), Ministerio de Economía y Competitividad (España), 2017, <http://www.dretpublic.urv.cat/media/upload/domain_89/arxius/Working\%20Paper\%20n\%C2\%BA\%204_1.pdf>, p. 32ss. [última visita el 31 de enero de 2017], en relación con la deuda climática.

${ }^{34}$ Vid. HORNBORG, A., "Zero-Sum World. Challenges in Conceptualizing Environmental Load Displacement and Ecologically Unequal Exchange in the World-System", International Journal of Comparative Sociology, vol. 50 (3-4), 2009, p. 237-262.
} 
Derecho público moderno; una reconsideración de las cuestiones relativas a la titularidad de los bienes y a la responsabilidad, lo que impacta sobre las nociones nucleares al entorno de las cuales se ha desarrollado la tradición civilista; así como una reinvención metodológica, más allá de las categorías y prácticas heredadas de la pandectística, que han configurado la cultura jurídica y la socialización profesional de los juristas continentales en el tránsito del Holoceno al Antropoceno. 